\title{
Predictions of mortality from mesothelial tumours in asbestos factory workers
}

\author{
MURIEL L. NEWHOUSE and G. BERRY \\ TUC Centenary Institute of Occupational Health, London School of Hygiene and Tropical \\ Medicine, Keppel Street, London WC1E 7HT and Medical Research Council, Pneumoconiosis \\ Unit, Llandough Hospital, Penarth, Glamorgan CF6 1XW
}

\begin{abstract}
Newhouse, M. L. and Berry, G. (1976). British Journal of Industrial Medicine, 33, 147-151. Predictions of mortality from mesothelial tumours in asbestos factory workers. Using the accumulated data on deaths from mesothelial tumours among cohorts of male and female factory workers at a London asbestos textile factory, the mortality from this cause up to the year 2000 AD has been predicted. The limitations of the methods used are pointed out, but it is estimated that for men the mortality due to mesothelial tumours will be between $7 \%$ and $11 \%$ of the total mortality and somewhat higher for women. The highest number of deaths from mesothelial tumours will occur during the 1980 s, thereafter the numbers will decline because of the decreasing size of the cohort resulting from general mortality.
\end{abstract}

For some years there has been concern about the magnitude of the risk of death from mesothelial tumours incurred by workers in the asbestos industry. The association between exposure, particularly to crocidolite asbestos, and development of this tumour has been recognized for the past 15 years (Wagner, Sleggs, and Marchand, 1960). In population-based studies of workers in various industries in different countries and exposed to different types of fibre and followed-up for differing periods, the proportion of deaths from mesothelioma has varied between $0.1 \%$ and $7 \%$ of the total mortality (Gilson, 1973). In the United Kingdom the Employment Medical Advisory Service, which maintains a mesothelioma register, reported 126 deaths in 1969 certified as mesothelial tumours increasing to 190 in 1973 (Department of Employment, 1975). In about two-thirds of these there was a history of exposure to asbestos dust (Greenberg and Lloyd Davies, 1974).

We have followed the mortality of past employees of an asbestos factory in the east end of London (Newhouse, 1969; Newhouse et al., 1972). The factory was opened in 1913 and continued to manufacture at the same site until 1968. The principal products were asbestos textiles and asbestos heat insulating materials. Chrysotile, amosite, and crocidolite asbestos were all used and mixed exposures were the rule.

Up to 30 September 1972, among 426 deaths in men who had survived for at least 10 years after first employment in the factory the cause of death in $\mathbf{3 1}$ was a mesothelial tumour, that is $7 \cdot 3 \%$ of all deaths. For women the corresponding figures were 14 out of $158,8.9 \%$. In all cases the diagnosis was validated by examination of necropsy reports and histological sections. Using these data an attempt has been made to predict the future mortality from mesotheliomata in order to assess the possible magnitude of this aspect of the health problem resulting from exposure to asbestos at this factory.

\section{Material and methods}

Groups of workers included in the study Approximately 3000 men and 700 women are included in the study. The men are all those first employed after the implementation of the first Asbestos Regulations in 1933 until 1964. The male cohort excludes laggers, about whom 
there is often uncertainty concerning previous exposure to asbestos dust before their employment by the company (Newhouse, 1969). The women are only those first employed between 1936 and 1942, a period selected when tracing past women employees was facilitated by war time records (Newhouse et al., 1972). Both men and women are grouped into two exposure categories: severe exposure, which includes those employed in opening, disintegrating, certain stores, textile and other production departments; and low-moderate exposure, including all other workers and office personnel employed in the factory. Length of exposure is divided into two categories: less than two years, and two years or more.

Factors influencing the mesothelioma incidence rate There are two important factors to be considered. The first is the lapse period, that is the length of the interval between first exposure and death from the tumour. Although exposure started as early as 1933 for some of the male cohort and between 1936 and 1942 for the women, no deaths from mesothelial tumours occurred until the quinquennium 1951-55; thereafter they became increasingly frequent (Table 1). By 30 September 1972, 45 deaths from these tumours had occurred in the two cohorts studied. In Table 2 the tumours are tabulated by time since first exposure; 23 of the mesotheliomata were of pleural origin and the remaining 22 of peritoneal origin. As the time of occurrence of the two types is similar they have not been considered separately. The mesotheliomata incidence rate per 100000 subject years at risk increases from six at between 10-15 years after first exposure to 318 among those with a follow-up period of 30 or more years (Table 2).

TABLE 1

Number of Deaths FRom Mesotheliomata PER QUINQUENNIUM

\begin{tabular}{c|c|c|c}
\hline Quinquennium & Men & Women & Total \\
\hline $1951-55$ & 1 & 1 & 2 \\
$1956-60$ & 4 & 1 & 5 \\
$1961-65$ & 9 & 2 & 11 \\
$1966-70$ & 13 & 8 & 21 \\
$1971-72$ & 4 & 2 & 6 \\
\hline (30 Sept.) & 4 & 14 & 45 \\
\hline Total & 31 & & \\
\hline
\end{tabular}

Secondly, both the degree and length of exposure are important, for men and women the rate increases both with longer periods of employment and with more intense exposure (Table 3 ). In those with low-moderate

TABLE 2

Mesothelioma Death Rate per 100000 Subject Years and Time Since First Exposure

\begin{tabular}{|c|c|c|c|c|c|c|c|}
\hline \multirow{2}{*}{ Years } & \multicolumn{2}{|c|}{ Men } & \multicolumn{2}{|c|}{ Women } & \multirow{2}{*}{ Total } & \multirow{2}{*}{$\begin{array}{c}\text { Subject } \\
\text { years }\end{array}$} & \multirow{2}{*}{$\begin{array}{c}\text { Rate per } \\
100000 \\
\text { subject years }\end{array}$} \\
\hline & Pleural & Peritoneal & Pleural & Peritoneal & & & \\
\hline $\begin{array}{l}10-15 \\
15-20 \\
20-25 \\
25-30 \\
30+\end{array}$ & $\begin{array}{l}0 \\
3 \\
4 \\
4 \\
3\end{array}$ & $\begin{array}{l}0 \\
3 \\
7 \\
3 \\
4\end{array}$ & $\begin{array}{l}1 \\
0 \\
3 \\
1 \\
4\end{array}$ & $\begin{array}{l}0 \\
0 \\
1 \\
3 \\
1\end{array}$ & $\begin{array}{r}1 \\
6 \\
15 \\
11 \\
12\end{array}$ & $\begin{array}{r}16167 \\
13438 \\
9862 \\
6423 \\
3772\end{array}$ & $\begin{array}{r}6 \\
45 \\
152 \\
171 \\
318\end{array}$ \\
\hline Total & 14 & 17 & 9 & 5 & 45 & & \\
\hline
\end{tabular}

TABLE 3

Mesothelioma Death Rates and Severity of Exposure

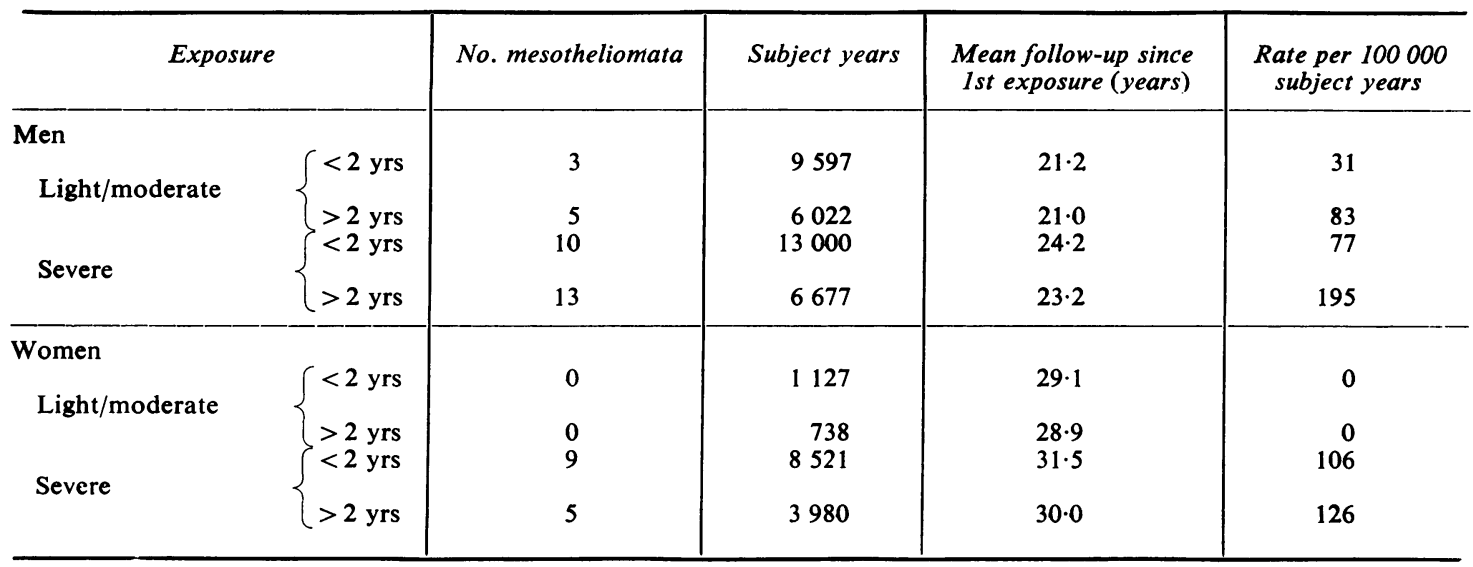


TABLE 4

Size of Groups and Relative Mortality Rates

\begin{tabular}{|c|c|c|c|c|c|}
\hline Exposur & & $\begin{array}{l}\text { Number alive } \\
\text { on 1.1.71 }\end{array}$ & $\begin{array}{l}\text { Number deceased } \\
\text { on } 30.9 .72\end{array}$ & $\begin{array}{c}\text { Total excess } \\
\text { mortality factor }\end{array}$ & $\begin{array}{l}\text { Mesothelioma rate/ } 100000 \\
\text { subject years (adjusted for } \\
\text { length of follow-up) }\end{array}$ \\
\hline $\begin{array}{l}\text { Men } \\
\text { Light/moderate } \\
\text { Severe }\end{array}$ & $\left\{\begin{array}{l}<2 \mathrm{yrs} \\
>2 \mathrm{yrs} \\
<2 \mathrm{yrs} \\
>2 \mathrm{yrs}\end{array}\right.$ & $\begin{array}{l}778 \\
478 \\
791 \\
377\end{array}$ & $\begin{array}{r}91 \\
68 \\
128 \\
139\end{array}$ & $\begin{array}{l}1.0 \\
1 \cdot 0 \\
1 \cdot 3 \\
1 \cdot 7\end{array}$ & $\begin{array}{r}39 \\
109 \\
76 \\
221\end{array}$ \\
\hline $\begin{array}{l}\text { Women } \\
\text { Light/moderate }\end{array}$ & $\left\{\begin{array}{l}<2 \mathrm{yrs} \\
>2 \mathrm{yrs} \\
<2 \mathrm{yrs} \\
>2 \mathrm{yrs}\end{array}\right.$ & $\begin{array}{r}43 \\
26 \\
333 \\
138\end{array}$ & $\begin{array}{l}17 \\
11 \\
67 \\
63\end{array}$ & $\begin{array}{l}1 \cdot 6 \\
1 \cdot 5 \\
1 \cdot 3 \\
2 \cdot 6\end{array}$ & $\begin{array}{r}0 \\
0 \\
80 \\
104\end{array}$ \\
\hline
\end{tabular}

*Ratio of observed deaths from all causes up to 30.9 .72 to number expected from national death rates

exposure and only short periods of employment the mesothelioma rate is about one-sixth of the rate of those with severe and long exposure. However the mean length of follow-up differs between the different groups, particularly between men and women because of the way the cohorts were defined, and these rates are not adjusted for these differences. Adjusted rates are given in Table 4.

\section{Projection into the future}

In predicting mortality from mesothelioma various assumptions are made: first that the total mortality of both male and female cohorts will be governed by the current age specific mortality rates of England and Wales except for a factor representing the excess mortality from all causes which has been observed to occur in these groups. This factor is dependent on the exposure category and is given the value of the ratio of the observed to expected deaths of those with more than 10 years' follow-up in each group (Table 4, column 3). Secondly that the mesothelioma incidence rate which has been observed to increase with time since first exposure up to $\mathbf{3 0}$ years (Table 2 ), will continue to increase as the follow-up increases further. Thirdly that the intensity of exposure to dust in any given job did not vary during the period, so that the risk of developing a mesothelioma is not dependent on the date when the worker was first exposed at the factory. As an alternative to this assumption, calculations have also been made assuming that those starting work after 1950 ran a risk of only half of those starting before this date, since there may have been an improvement in dust control at about this time.

In order to progress further it is necessary to specify in detail the relationship between mesothelioma risk and time since first exposure to asbestos. A model relating tumour rate and time which has been shown to be applicable to a range of human cancer (Cook, Doll, and Fellingham, 1969) and also to asbestos-induced mesotheliomata in rats (Berry and Wagner, 1969), has been used. In the model, mesothelioma risk $(\mathrm{m})$ increases with time since first exposure $(t)$ according to:

$$
\mathrm{m}=\mathrm{c}(\mathrm{t}-\mathrm{w})^{\mathbf{k}}
$$

where $c, w$, and $k$ are constants. There is some theoretical justification for using this formula (Pike, 1966), and on this basis both the parameter w, which is the minimum lapse period and the power $\mathrm{k}$ are independent of the degree of exposure. Pike and Doll (1965) confirm that for lung cancer in smokers

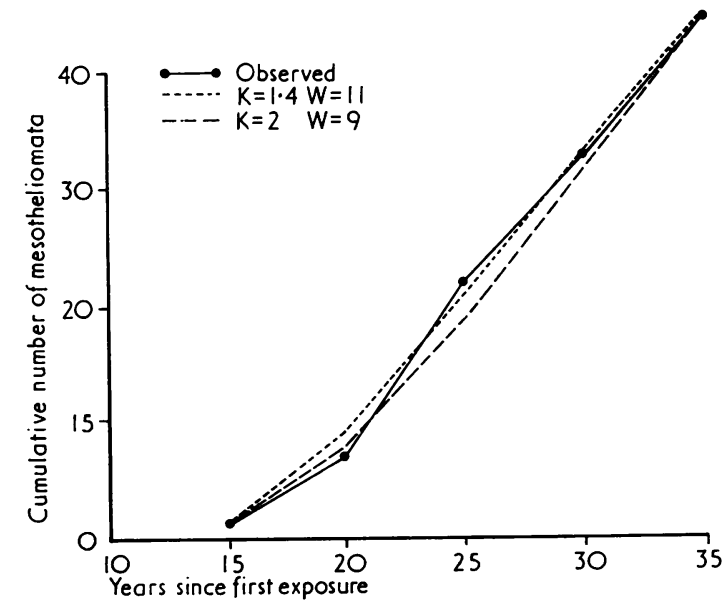

FIG. 1. Fit of model to data. 
$\mathbf{k}$ and $\mathbf{w}$ were independent of the number of cigarettes smoked a day. Therefore different risks in the different exposure groups are indicated by different values of $c$.

The constants $\mathrm{k}, \mathrm{w}$, and the 8 values of $\mathrm{c}$ have been estimated from the data already presented in Tables 2 and 3. The best estimates are $k=1.4$, $\mathrm{w}=11$ years. However the estimates $\mathrm{k}=2, \mathrm{w}=9$ fit the data almost as well, and the higher value of $k$ is in agreement with the animal experiments (Berry and Wagner, 1969). The fit of the model to the data is shown in Fig. 1 for both sets of estimates, and the projection is carried out with both sets. From the estimates of c, mesothelioma rates, adjusted for length of follow-up, were calculated by applying the fitted rates for each group and period of follow-up

TABLE 5

Total Number of Subjects at Risk and Number WITH MORE THAN 20 Years' Follow-UP Since FIRST EXPOSURE

\begin{tabular}{c|c|c|c|c}
\hline \multirow{1}{*}{ Year } & \multicolumn{2}{|c|}{ Men } & \multicolumn{2}{c}{ Women } \\
\cline { 2 - 5 } & Total & $\begin{array}{r}20 \text { years' } \\
\text { follow-up }\end{array}$ & Total & $\begin{array}{c}20 \text { years' } \\
\text { follow-up }\end{array}$ \\
\hline 1951 & 1586 & 0 & 677 & 0 \\
1961 & 2503 & 507 & 636 & 407 \\
1971 & 2424 & 1250 & 540 & 540 \\
\hline 1976 & 2224 & 1604 & 477 & 477 \\
1986 & 1699 & 1699 & 328 & 328 \\
1996 & 1061 & 1061 & 156 & 156 \\
\hline
\end{tabular}

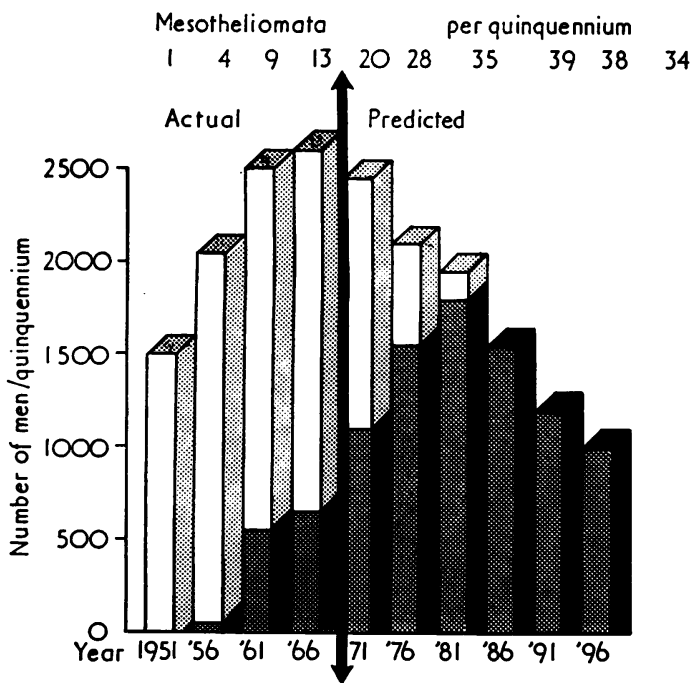

FIG. 2. Three-dimensional histogram showing (shaded areas) number of men with 20 years' or longer follow-up. to the overall distribution of follow-up. These adjusted rates are almost independent of the estimates used for $\mathrm{k}$ and $\mathrm{w}$ and are given in Table 4.

When considering the projection into the future the risk increases very markedly as time progresses after first exposure, but on the other hand the number of subjects at risk decreases progressively after recruitment until the study ends, due to mortality from all causes (Table 5). Also shown in Table 5 are the numbers of subjects with more than 20 years' follow-up since first exposure (shown graphically for men in Figure 2), that is, those at high risk. They do not reach their highest values until 1981 and 1971 for men and women respectively.

The estimated number of mesotheliomata using the two sets of estimates of $k$ and $w$ and also with reduction in exposure level after 1950 are shown in Table 6. The estimate $k=1.4$ gives the lowest values, the alternative estimate of $k=2$ increases the

TABLE 6

Projected Numbers of Mesotheliomata

\begin{tabular}{l|c|c|c|c|c|c}
\hline \multirow{2}{*}{ Years } & \multicolumn{4}{|c|}{ Men } & \multicolumn{2}{c}{ Women } \\
\cline { 2 - 7 } & $(a)$ & $(b)$ & $(c)$ & $(d)$ & $(a)$ & $(b)$ \\
\hline $1971-75$ & 18 & 20 & 16 & 19 & 7 & 8 \\
$1976-80$ & 23 & 28 & 21 & 25 & 8 & 10 \\
$1981-85$ & 27 & 35 & 23 & 30 & 8 & 11 \\
$1986-90$ & 28 & 39 & 23 & 33 & 8 & 12 \\
$1991-95$ & 27 & 38 & 21 & 31 & 7 & 10 \\
$1996-2000$ & 23 & 34 & 17 & 26 & 5 & 8 \\
\hline Total & 146 & 194 & 121 & 164 & 43 & 59 \\
\hline
\end{tabular}

Alternative projections are given, according to the estimates used for $\mathrm{k}$ and $\mathrm{w}$, and for men with risk reduced to half for those first expected after 1950: (a) $\mathrm{k}=1.4, \mathrm{w}=9,(b) \mathrm{k}=2$, $\mathbf{w}=11,(c)$ as $(a)$ but with reduced risk after 1950, (d) as $(b)$ but with reduced risk after 1950

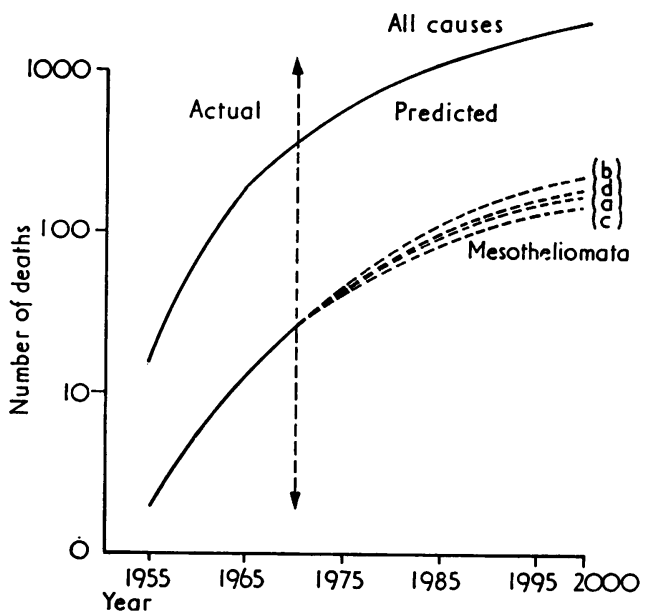

FIG. 3. Cumulative mortality for men (predictions as defined in Table 6). 
number of tumours by about $35 \%$. If the risk was halved for those men first employed at the factory after 1950 then the projected number of tumours is reduced by about $15 \%$.

Finally it is of interest to consider the cumulative mortality of these workers, both from all causes and that due to the specific occupational cancer. This is shown for men in Fig. 3. For the years 1971-75 we have incomplete data up to mid-1973; so far 13 deaths from mesotheliomata have been confirmed.

\section{Discussion}

Projection into 30 years ahead is essentially a hazardous process, and our particular case based on 45 mesotheliomata observed over 20 years is clearly no exception. Several sources of error may be envisaged. The mortality from all causes in the two cohorts may not continue to have the same relationship with national rates as observed in the past, and the national rates themselves will probably change during the next 30 years. The estimates of the parameters of the model are imprecise because of the limited amount of data so far obtained. The dust hazard within the factory may also have changed during the period of exposure. We have presented alternative estimates to cover to some extent the last two possibilities. The resulting range of projections illustrates the uncertainty of the process. For men $7 \cdot 3 \%$ of the deaths since 1951 which had occurred by 1970 were due to mesotheliomata. By the year $2000 \mathrm{AD}$ the range of values is between $7 \cdot 3 \%$ and $10.8 \%$ and the total number of predicted tumours during the period 1971-2000, 121 to 194. For women $8.8 \%$ of the deaths by 1970 were due to mesotheliomata, and by $2000 \mathrm{AD}$ we predict this percentage to be between 9.1 and 12.0 , with 42 to 59 predicted tumours in the period 1971-2000. Even with the lowest estimates the peak incidence of mesotheliomata is not predicted to occur until the $1980 \mathrm{~s}$ and the incidence at the turn of the century will be similar to the present level. In addition there will continue to be an excess of lung cancer due to asbestos and deaths due to asbestosis. It should be stressed that the population we are considering were all first exposed to asbestos before 1964 and most of them earlier than 1951. Therefore the conditions responsible are not those which should be achieved today. The evidence of a dose response relationship (Table 3) shows that improved control of the factory environments at present and in the future should markedly reduce risks, and relatively recent improved standards (British Occupational Hygiene Society, 1968) and the 1969 Asbestos Regulations (Department of Employment and Productivity, 1969) should help in this direction. However the long period of time over which high exposures in the past show their effect must act as a spur to be as stringent as possible in the control of asbestos exposure at all times.

We would like to thank Dr J. C. Gilson and Professor R. S. F. Schilling for their help and advice, and Dr W. Smither and the Cape Industries for their co-operation.

\section{References}

Berry, G. and Wagner, J. C. (1969). The application of a mathematical model describing the times of occurrence of mesotheliomas in rats following inoculation with asbestos. British Journal of Cancer, 23, 582-586.

British Occupational Hygiene Society (1968). Hygiene standards for chrysotile asbestos dust. Annals of Occupational Hygiene, 11, 47-71.

Cook, P. J., Doll, R., and Fellingham, S. A. (1969). A mathematical model for the age distribution of cancer in man. International Journal of Cancer, 4, 93-112.

Department of Employment (1975). Employment Medical Advisory Service. Report of the Work of the Service for 1973 and 1974, p. 29. HMSO, London.

Department of Employment and Productivity (1969). Statutory Instruments No. 690, Factories: The Asbestos Regulations, 1969. HMSO, London.

Gilson, J. C. (1973). Asbestos cancer and future hazards. Proceedings of the Royal Society of Medicine, 66, 395-403.

Greenberg, M. and Lloyd Davies, T. A. (1974). Mesothelioma Register 1967-68. British Journal of Industrial Medicine, 31, 91-104.

Newhouse, M. L. (1969). A study of the mortality of workers in an asbestos factory. British Journal of Industrial Medicine, 26, 294-301.

-, Berry, G., Wagner, J. C., and Turok, M. E. (1972). A study of the mortality of female asbestos workers. British Journal of Industrial Medicine, 29, 134-141.

Pike, M. C. (1966). A method of analysis of a certain class of experiments in carcinogenesis. Biometrics, 22, 142-161.

- and Doll, R. (1965). Age at onset of lung cancer: significance in relation to smoking. Lancet, 1, 665-668.

Wagner, J. C., Sleggs, C. A., and Marchand, P. (1960). Diffuse pleural mesothelioma and asbestos exposure in the North Western Cape Province. British Journal of Industrial Medicine, 17, 260-271.

Received for publication 5 January 1976.

Accepted for publication 1 February 1976. 